Article

\title{
Five Surfactin Isomers Produced during Cheonggukjang Fermentation by Bacillus pumilus HY1 and Their Properties
}

\author{
Su-Young Hong ${ }^{1}$, Dong-Hee Lee ${ }^{2}$, Jin-Hwan Lee ${ }^{3}$, Md. Azizul Haque ${ }^{4}$ and Kye-Man Cho ${ }^{5, *}$ \\ 1 SBT Business Division, Food Science Research Institute, Kolmar BNH Inc., Sejong 30003, Korea; \\ syhong@kolmarbnh.co.kr \\ 2 Industry Academy Cooperation Foundation, Andong National University, Andong 36729, Korea; \\ dhlee@andong.ac.kr \\ 3 Department of Life Resources Industry, Dong-A University, Busan 49315, Korea; schem72@dau.ac.kr \\ 4 Department of Biochemistry \& Molecular Biology, Hajee Mohammad Danesh Science \& Technology \\ University, Dinajpur 5200, Bangladesh; helalbmb2016@hstu.ac.bd \\ 5 Department of Food Science, Gyeongsang National University, Jinju 52725, Korea \\ * Correspondence: kmcho@gnu.ac.kr; Tel.: +82-010-7170-3272 or 82-55-772-3272
}

Citation: Hong, S.-Y.; Lee, D.-H.; Lee, J.-H.; Haque, M..A.; Cho, K.-M. Five Surfactin Isomers Produced during Cheonggukjang Fermentation by Bacillus pumilus HY1 and Their Properties. Molecules 2021, 26, 4478. https://doi.org/10.3390/ molecules 26154478

Academic Editor: James Barker

Received: 28 May 2021

Accepted: 20 July 2021

Published: 24 July 2021

Publisher's Note: MDPI stays neutral with regard to jurisdictional claims in published maps and institutional affiliations.

Copyright: (c) 2021 by the authors. Licensee MDPI, Basel, Switzerland. This article is an open access article distributed under the terms and conditions of the Creative Commons Attribution (CC BY) license (https:/ / creativecommons.org/licenses/by/ $4.0 /)$.

\begin{abstract}
The cyclic lipopeptide produced from Bacillus pumilus strain HY1 was isolated from Korean soybean sauce cheonggukjang. The chemical structures of the surfactin isomers were analyzed using matrix-assisted laser desorption ionization time-of-flight mass spectrometry (MALDI-TOF MS) and electrospray ionization tandem mass spectrometry (ESI-MS/MS). The five potential surfactin isoforms were detected with protonated masses of $m / z$ 994.7, 1008.7, 1022.7, 1036.7, and 1050.7 and different structures in combination with $\mathrm{Na}^{+}, \mathrm{K}^{+}$, and $\mathrm{Ca}^{2+}$ ions. ESI-MS/MS analysis revealed that the isolated surfactin possessed the precise amino acid sequence LLVDLL and hydroxyl fatty acids with 12 to 16 carbons. The surfactin content during cheonggukjang fermentation increased from 0.3 to $51.2 \mathrm{mg} / \mathrm{kg}$ over $60 \mathrm{~h}$ of fermentation. The mixture of five surfactin isoforms of cheonggukjang inhibited the growth of two cancer cell lines. The growth of both MCF-7 and Caco-2 cells was strongly inhibited with $100 \mu \mathrm{g} / \mu \mathrm{L}$ of surfactin. This study is the first-time report of five surfactin isomers of Bacillus pumilus strain HY1 during Korean soybean sauce cheonggukjang fermentation, which has cytotoxic properties.
\end{abstract}

Keywords: Bacillus pumilus HY1; solid-state fermentation; cheonggukjang; surfactin; mass spectrum; cytotoxic effect

\section{Introduction}

Surfactins are cyclic lipopeptide (CLP) biosurfactants produced by several Bacillus strains including B. subtilis, B. amyloliquefaciens, B. pumilus, B. licheniformis, and B. mojavensis [1-5]. Surfactin is produced non-ribosomally by multienzyme complexes called nonribosomal peptide synthetases [6]. The small microbial peptides produced via nonribosomal pathways had demonstrated potent biological activities and growing economic value in uses such as drugs, e.g., antibiotics [7], cytotoxic benzolactones [8], alkaloids [9], or as food additives [10]. Surfactin is composed of one $\beta$-hydroxy fatty acid molecule with a long fatty acid moiety, linked to a seven amino acid peptide to form a lactone ring [11]. It exhibits diverse biological activities, including antitumoral [4,12,13], antiviral [14], antibacterial [15], antimycoplasmal [16], hemolytic [17], and fibrinolytic activities [18]. It also inhibits fibrin clot formation [19], phosphodiesterase activity [20], cyclic adenosine monophosphate (cAMP) signaling [20], and platelet and spleen cytosolic phospholipase A2 (PLA2) activity [21].

Fermented soybean is a good source of hydrolyzed peptides, protein, lipids, and many Koreans consume soybeans for their health benefits, which includes reducing arterial stiffness. There are several types of fermented soybean foods, including meju (soybean 
cake), doenjang (soybean paste), kanjang (soybean sauce), and cheonggukjang (soybean cook). Meanwhile, several reports have shown the antioxidant, antimicrobial, antigenotoxic, blood pressure lowering, and anti-diabetic activities of cheonggukjang [22,23]. In a previous study, we reported the production of surfactin from a potential probiotic, Bacillus subtilis CSY191, during the fermentation of cheonggukjang, and the purified surfactin exhibited anticancer activity against human breast cancer MCF-7 cells [4]. The identification and separation of the various beneficial metabolites in chenoggukjang, e.g., surfactin and micropeptide, enables a demonstration of their health benefits and promotes the development of distinct, functional products for the food industry.

In the present study, surfactin was purified from strain B. pumilus HY1, a bacterial strain commonly detected in traditional Korean fermented soy sauce (kanjang). The surfactin was fractionated through TLC and RP-HPLC and characterized using mass spectrometry. The concentration of surfactin during the fermentation of cheonggukjang by B. pumilus HY1 was determined. Finally, the antiproliferative activity of the surfactin extraction of cheonggukjang against the cancer cell lines MCF-7 (human breast cancer line) and Caco-2 (human intestinal cancer line) was studied.

\section{Results}

2.1. Isolation of Surfactin from B. pumilus $H Y 1$

The production spectrum of surfactin by the strain Bacillus pumilus HY1 was recorded and represented in the Figure 1. In fact, the negative control Escherichia coli DH5 $\alpha$ lacks surfactin-producing genes, and did not shown any halo zone in the agar plate.

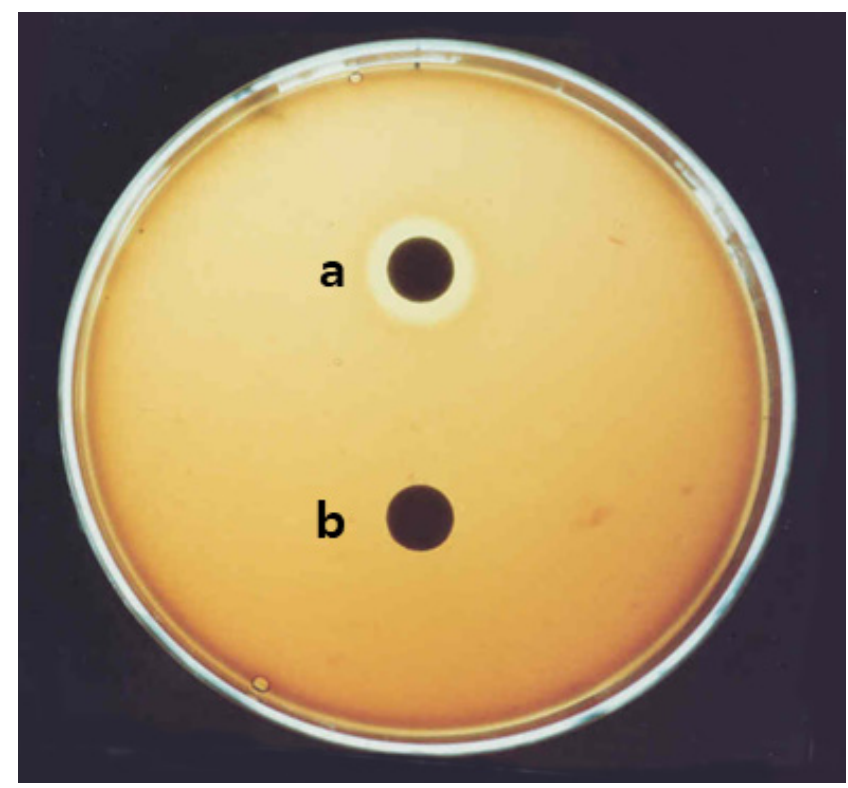

Figure 1. Surfactin production test of Bacillus pumilus HY1. The strain HY1 grown on defibrinogen sheep blood agar at $37^{\circ} \mathrm{C}$ for 24 h: (a) Bacillus pumilus HY1; and (b) Escherichia coli DH5 $\alpha$. The Escherichia coli $\mathrm{DH} 5 \alpha$ were used as negative control of surfactin production in agar plate.

The surfactin was produced during the fermentation of high producer B. pumilus HY1 in No. 3 medium. Acid-precipitated and methanol-extracted bacterial cells were concentrated and chromatographed. The TLC of the obtained CLP material was performed on silica gel 60, using solvent (chloroform/methanol/water $=65: 25: 4, v / v / v$ ) as the mobile phase, which showed a broad spot with a $R f$ value of 0.5 to 0.55 . Analytical gel filtration of the entire surfactin mixture was performed using surfactin from B. subtilis (Sigma-Aldrich, Inc.) as a size marker, yielding a molecular mass of 1036. Reverse phase HPLC was used to analyze surfactin, followed by purification at $214 \mathrm{~nm}$ (Figure 2). 

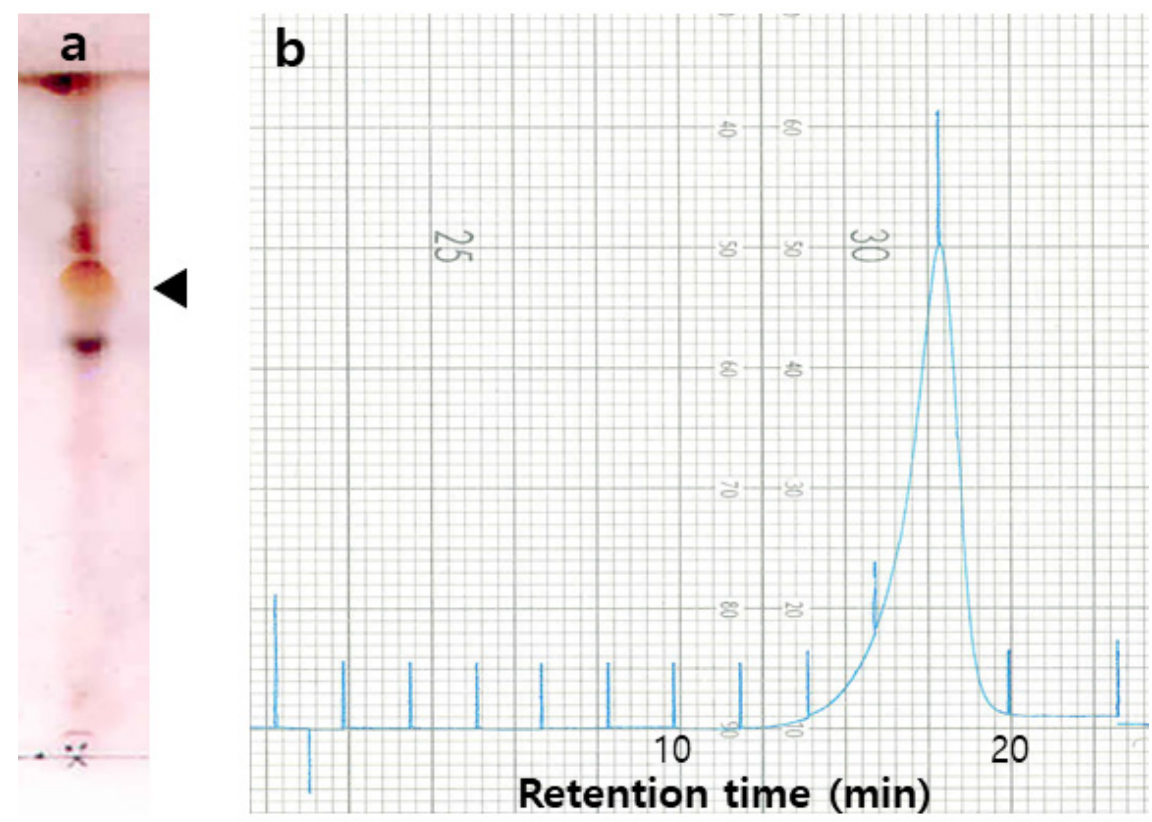

Figure 2. TLC and HPLC profiles of the surfactin produced by Bacillus pumilus HY1: (a) TLC profiles as follow: Developing solvent—chloroform:methanol:water $=65: 25: 4(v / v / v)$ drops and visualization$10 \% \mathrm{H}_{2} \mathrm{SO}_{4}$ in water; and (b) HPLC profiles as follow: Eluent solvent-acetonitrile:water = 1:1 $(v / v)$, flow rate $-2.5 \mathrm{~mL} / \mathrm{min}$, and absorbance $-214 \mathrm{~nm}$.

\subsection{Mass Spectrum of Surfactin by B. pumilus HY1}

The purified surfactin was analyzed and identified using MALDI-TOF MS, ICP MS, and ESI MS/MS. The MALDI-TOF MS displayed $[\mathrm{M}+\mathrm{H}]^{+}$peaks at $\mathrm{m} / z$ 994.7, 1008.7, $1022.7,1036.7$, and 1050.7, and these peaks were separated by $\mathrm{m} / \mathrm{z} 14$. The MALDI-TOF MS displayed the groups of peaks at $m / z$ 1016.58, 1030.58, 1044.61, 1058.62, and 1072.62, which could reflect the isoform ensembles of surfactin (Figure 3). The surfactin contained a mixture of structural analogs with a mass difference of $14 \mathrm{Da}$. Most of the peaks could reflect essentially pure surfactin isoforms using MALDI-TOF MS to detect the distribution of the molecular ions in these fractions and the assignment of the ions to different surfactin species. Based on the mass spectrometric data, the surfactin isoforms were eluted according to their hydrophobicities. For the large peak appearing in fractions in front of the five main peaks, the main parent ions detected at $m / z 1016.5811,1030.5833,1044.6104,1058.6250$, and 1072.6289 were attributed to a small amount of the sodium adduct of a valine- 7 surfactin. The low mass peaks at $m / z 1032.5869,1046.5831,1060.6001,1074.6023$, and 1088.6222 represented the potassium adduct of these species. The other mass peaks at $m / z 1033.5630$, $1047.5841,1061.6024,1075.5997$, and 1089.8287 represented the calcium adduct of these species (Figure 3 ). These peaks contained essentially pure $C_{12}$ to $C_{16}$ surfactin species, respectively. The purified surfactin was analyzed using ICP MS, and potassium and calcium ions were detected (Table 1). These results were consistent with those of the MALDI-TOF MS analysis, suggesting the presence of ions. The four amino acids Asp, Glu, Val, and Leu at a ratio 1:1:1:4 were detected in the purified HPLC fraction of surfactin after hydrolysis and derivatization using Marfey's reagent. The amino acid composition corresponded to that of surfactin. For the detailed analysis, the peptide sequence of surfactin was deduced after interpreting the ESI-MS/MS spectrum of the precursor ions $\mathrm{m} / \mathrm{z} 994.7081,1008.7334$, $1022.7391,1036.7528$, and 1050.7487 , assuming the preferential cleavage of the ring opening in the lactone bond in the collision chamber (Figure 4). 


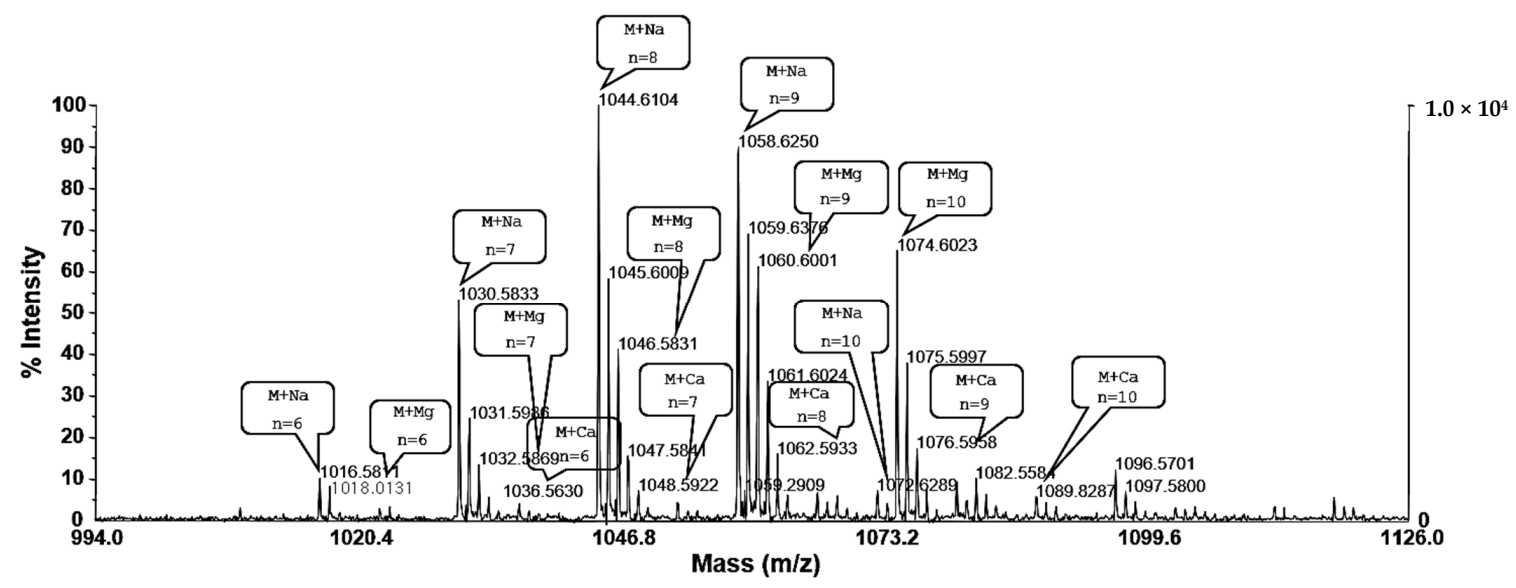

Figure 3. MALDI-TOF mass spectrum of the surfactin produced by Bacillus pumilus HY1: The lipopeptide appeared as a complex mixture of several isoforms. Sodium $(\mathrm{Na})$, potassium $(\mathrm{K})$, and calcium $(\mathrm{Ca})$ ions were detected.
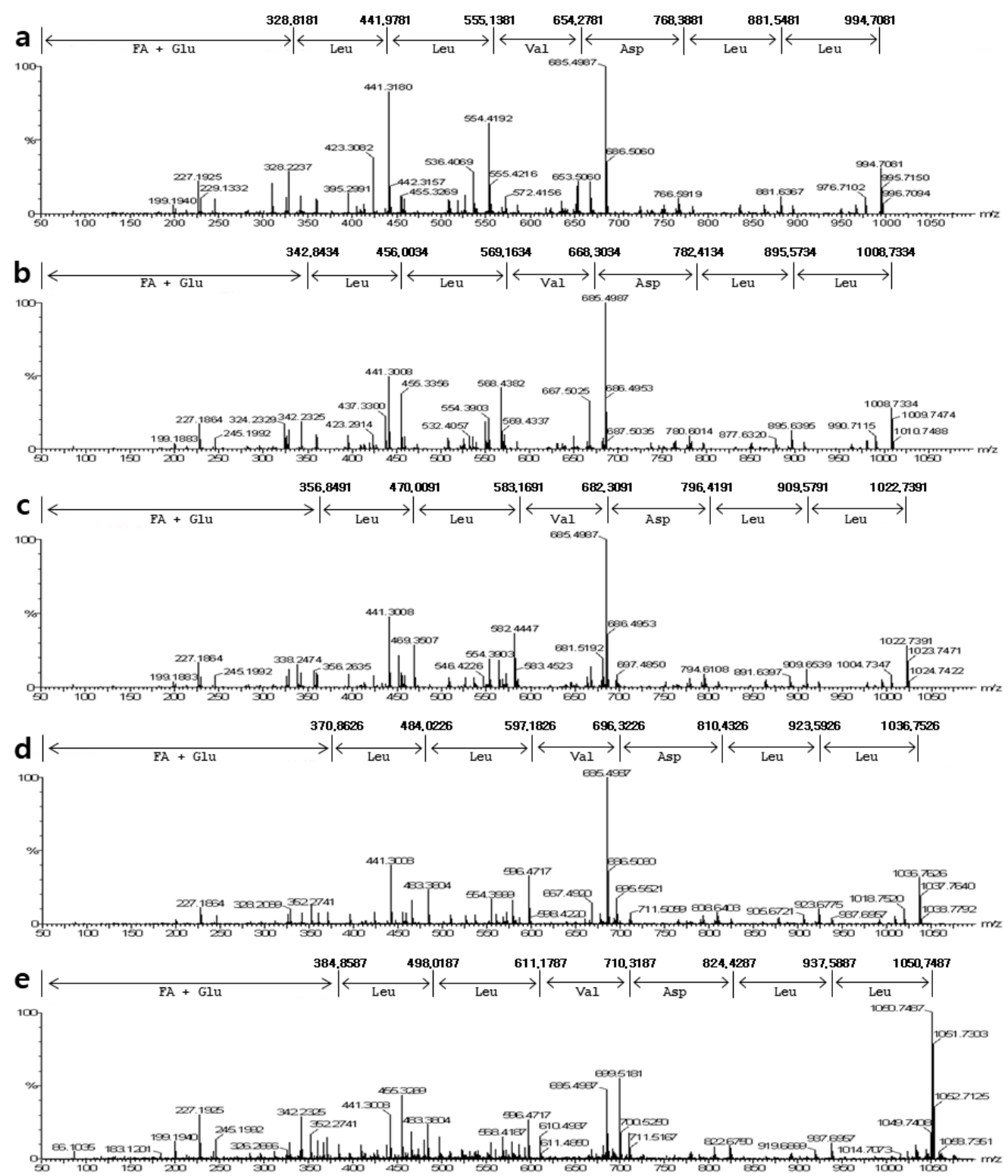

Figure 4. ESI tandem mass spectrometry fragmentation of surfactin isomers: Peptide sequences of five surfactin isomers were identified based on the MS/MS spectrum of the precursor ion $m / z$ 994.7081, 1008.7334, 1022.7391, 1036.7528, and 1050.7487. (a) $994.7081 \mathrm{~m} / \mathrm{z}$; (b) $1008.7334 \mathrm{~m} / \mathrm{z}$; (c) $1022.7391 \mathrm{~m} / \mathrm{z}$; (d) $1036.7528 \mathrm{~m} / \mathrm{z}$; and (e) $1050.7487 \mathrm{~m} / \mathrm{z}$. 
Table 1. ICP mass spectrum of surfactin isomers from surfactin produced by Bacillus pumilus HY1.

\begin{tabular}{cccc}
\hline Elements & Concentration $(\mathbf{p p b})$ & Elements & Concentration (ppb) \\
\hline $\mathrm{Al}$ & 0.0 & $\mathrm{P}$ & 1121.5 \\
$\mathrm{~B}$ & 133.6 & $\mathrm{Rb}$ & 0.0 \\
$\mathrm{Br}$ & 0.0 & $\mathrm{Re}$ & 0.0 \\
$\mathrm{Ca}$ & 1509.6 & $\mathrm{Ru}$ & 94.4 \\
$\mathrm{Cd}$ & 0.0 & $\mathrm{~S}$ & $348,218.9$ \\
$\mathrm{Cr}$ & $122,736.5$ & $\mathrm{Sc}$ & $74,514.2$ \\
$\mathrm{Cs}$ & 0.0 & $\mathrm{Se}$ & $1,112,974.3$ \\
$\mathrm{Cu}$ & 0.0 & $\mathrm{Sn}$ & 115.1 \\
$\mathrm{Ge}$ & 194.9 & $\mathrm{Sr}$ & 0.0 \\
$\mathrm{Hg}$ & 26.9 & $\mathrm{Ta}$ & 2.9 \\
$\mathrm{I}$ & 1375.0 & $\mathrm{Ti}$ & 580.2 \\
$\mathrm{~K}$ & 89.4 & $\mathrm{U}$ & 0.0 \\
$\mathrm{Li}$ & 122.4 & $\mathrm{~V}$ & 0.0 \\
$\mathrm{Mg}$ & 5634.3 & $\mathrm{~W}$ & 44.7 \\
$\mathrm{Mn}$ & 0.0 & $\mathrm{Y}$ & 538.1 \\
$\mathrm{Mo}$ & 0.0 & $\mathrm{Yb}$ & 0.0 \\
$\mathrm{Na}$ & 6446.2 & $\mathrm{Zn}$ & 2351.4 \\
$\mathrm{Os}$ & 0.0 & & \\
\hline
\end{tabular}

\subsection{Changes in Viable Cell Number of B. pumilus HY1 and Surfactin Concentration during Cheonggukjang Fermentation}

Changes in the bacterial viable cell numbers and surfactin concentration during the fermentation of cheonggukjang are shown in Figure 5. As a result of HPLC analysis in Figure 5a, the surfactin peak was detected at approximately $8.17 \mathrm{~min}$. The level of viable cells in fermented cheonggukjang ranged from $3.0 \log \mathrm{CFU} / \mathrm{mL}(0 \mathrm{~h})$ to $11.7 \log \mathrm{CFU} / \mathrm{mL}(60 \mathrm{~h})$. Correspondingly, the concentration of surfactin in cheonggukjang fermentation increased from $0.3 \mathrm{mg} / \mathrm{kg}$ in the initial stage to $51.2 \mathrm{mg} / \mathrm{kg}$ after $60 \mathrm{~h}$. The surfactin concentration peaked at $48.4 \mathrm{mg} / \mathrm{kg}$ at $48 \mathrm{~h}$ and increased slightly at the end of fermentation (Figure $5 \mathrm{~b}$ ).
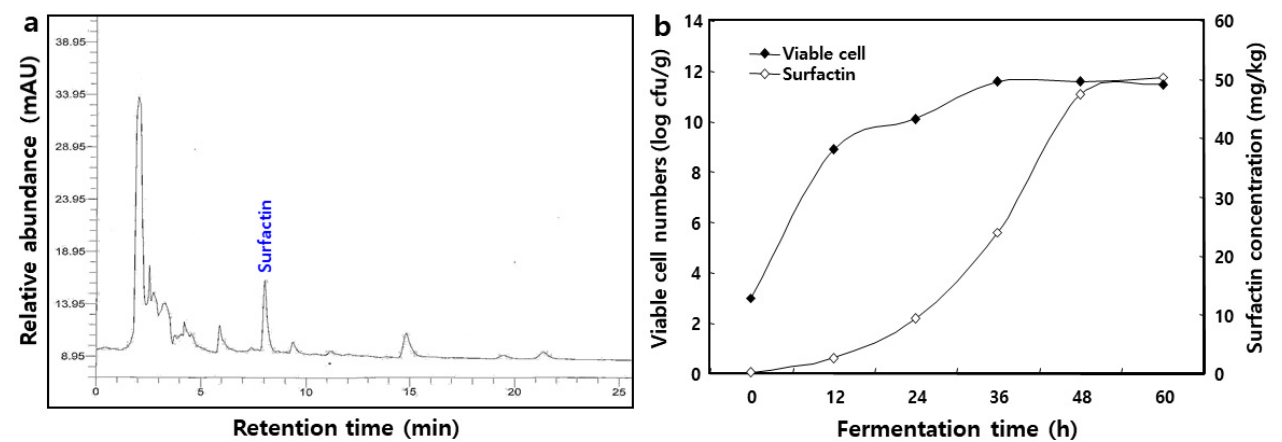

Figure 5. Typical HPLC chromatogram of the $95 \%$ methanol extracts in cheonggukjang (fermentation time: $60 \mathrm{~h}$ ) and changes in the viable cell numbers and surfactin concentration during fermentation of chenonggujang by Bacillus pumilus HY1. (a) HPLC chromatogram; and (b) viable cell numbers and surfactin concentration.

\subsection{Effect of MSIC on the Growth of Cancer Cells}

We used the well-characterized MTT assay to assess the metabolic activity of cells, to determine whether surfactin could inhibit the growth of MCF-7 and Caco-2 cells, two cancer cell lines. MCF-7 and Caco-2 cells were incubated with MSIC at concentrations ranging from 0 to $120 \mu \mathrm{g} / \mu \mathrm{L}$ of surfactin, as shown in Figure 6. The MSIC inhibited the growth of cancer cells in a concentration-dependent manner. Morphological changes provide the most direct criteria for recognizing the apoptotic process. As shown in Figure 7, membrane blebbing and DNA fragmentation were observed $24 \mathrm{~h}$ after exposure to MSIC $(100 \mu \mathrm{g} / \mu \mathrm{L}$ of surfactin). A protrusion-like shape began to form a branch as the shape of 
the cell lengthened. Moreover, it resulted in very severe morphological deformation of cells such as membrane shrinking and the rounding up of cells (Figure 7). As shown in Figure 8, DNA laddering, typical of the cells in which apoptosis occurred, was observed in the cancer cells with surfactin treatment. This means that endonuclease was activated by the surfactin treatment and then chromosomal DNA fragmented.
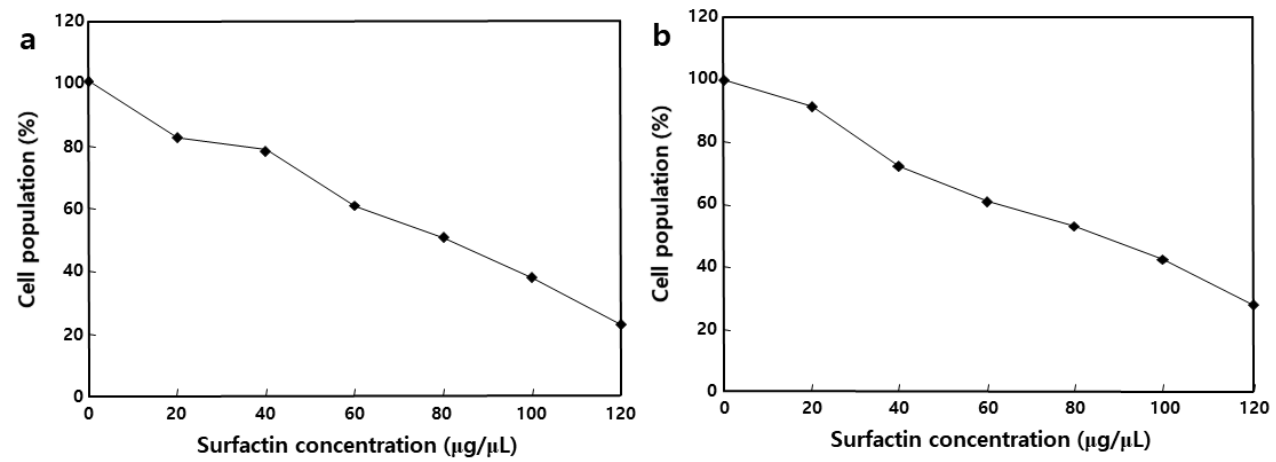

Figure 6. Cell population of human breast (MCF-7) and intestinal (Caco-2) cancer cell lines according to treatment of different surfactin concentrations: (a) mixture of five surfactin isoforms of cheonggukjang-treated MCF-7 cells; and (b) mixture of five surfactin isoforms of cheonggukjang-treated Caco-2 cells.
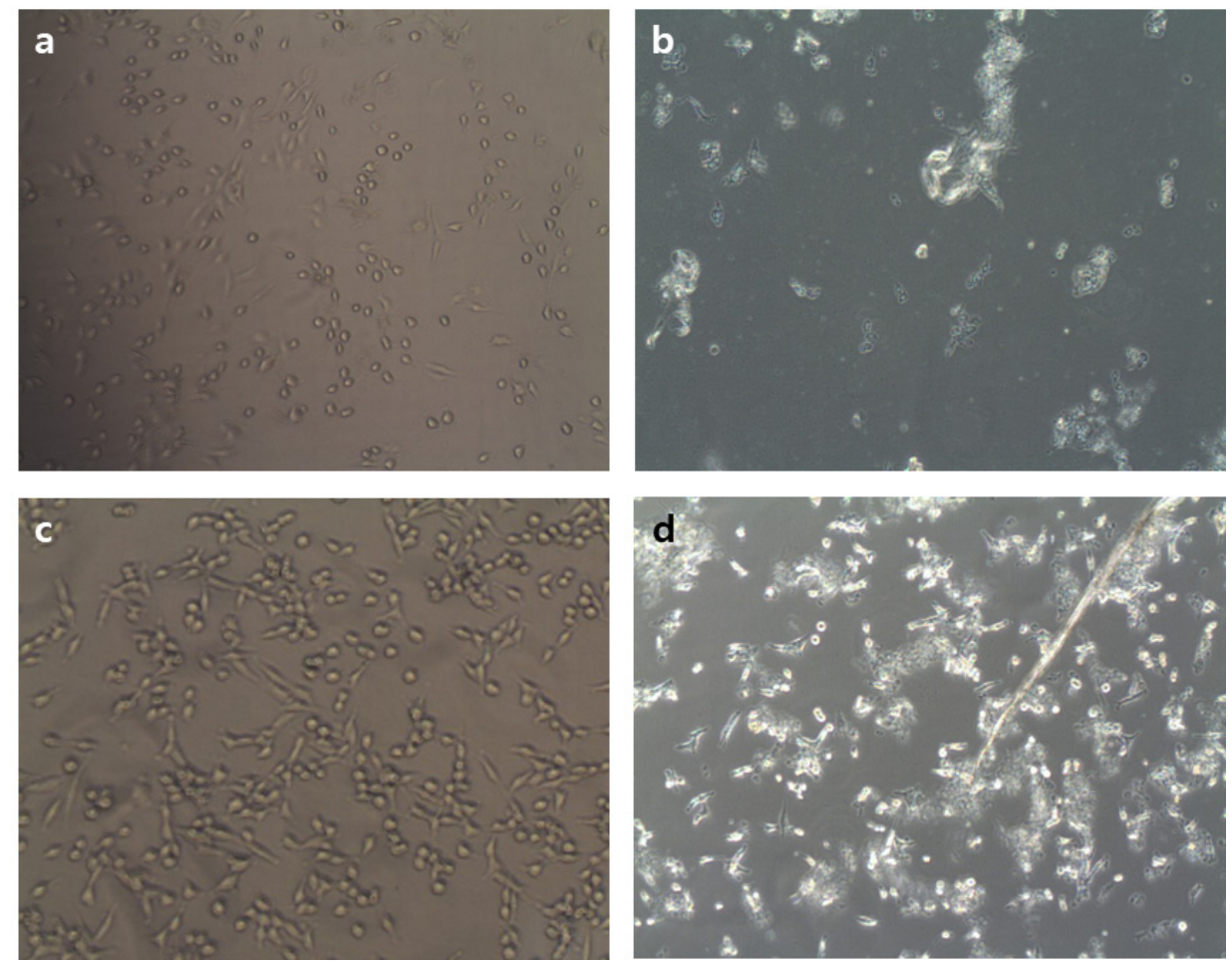

Figure 7. Cytotoxicity test of human breast (MCF-7) and intestinal (Caco-2) cancer cell lines by treatment of mixture of five surfactin isoforms of cheonggukjang (MSIC): (a) MCF-7 cells (control); (b) MSIC-treated MCF-7 cells $(100 \mu \mathrm{g} / \mu \mathrm{L})$; (c) Caco-2 cells (control); and (d) MSIC-treated Caco-2 cells $(100 \mu \mathrm{g} / \mu \mathrm{L})$. 


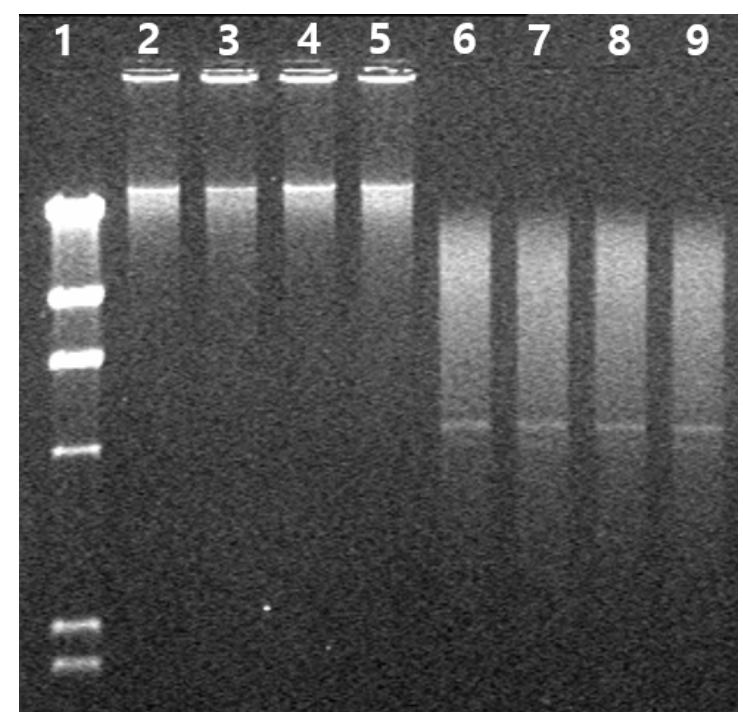

Figure 8. DNA fragmentation of human breast (MCF-7) and intestinal (Caco-2) cancer cell lines by treatment of mixture of five surfactin isoforms of cheonggukjang (MSIC): Line 1, size marker; line 2 and 3, MCF-7 cells (control); line 4 and 5, Caco-2 cells (control); line 6 and 7, MSIC-treated MCF-7 cells $(100 \mu \mathrm{g} / \mu \mathrm{L})$; and line 8 and 9, MSIC-treated Caco-2 cells $(100 \mu \mathrm{g} / \mu \mathrm{L})$.

\section{Discussion}

In the present study, we investigated the purification of surfactin from B. pumilus HY1, the CLP (such as iturin and surfactin) producing strain isolated from kanjang [24]. The surfactins were fractionated using high resolution RP-HPLC and were determined by MADI-TOF MS and ESI-MS/MS. Moreover, the surfactin concentration was confirmed during cheonggukjang fermentation by B. pumilus HY1, and the cytotoxic effect of SECs against MCF-7 and Caco-2 cells was examined. Surfactin is a cyclic heptalipopeptide with the sequence Glu-Leu-Leu-Val-Asp-Leu, a terminal Leu linked to a $\beta$-hydroxy fatty acid residue, with amide (Glu) and lactone (Leu) bonds forming a cyclic structure. Three isoforms in natural surfactin with substitution of the L-Leu in position 7 of the main product by L-Val and L-Ile were characterized using 2D NMR spectroscopy in combination with chemical analysis [25]. The molecular network was distributed with known compounds from the Global Natural Products Social (GNPS) molecular networking standard library, where one molecular family (group of related precursor ions) contained the standard of the compound's surfactin class [26]. The surfactin of B. pumilus HY1 possessed five potential isoforms with protonated masses of 994.7, 1008.7, 1022.7, 1036.7, and $1050.7 \mathrm{~m} / \mathrm{z}$ and different structures in combination with $\mathrm{Na}^{+}, \mathrm{K}^{+}$, and $\mathrm{Ca}^{2+}$ ions (Figure 3). These results are consistent with data obtained from the analysis of the amino acid composition and showed that surfactin purified from B. pumilus HY1 was identical to surfactin produced from B. subtilis and B. amyloliquefaciens [4,27]. ESI-MS/MS analysis revealed that the structure of fatty acid was simulated, and the results indicated that surfactin was determined as a homologous series of hydroxy fatty acids with $12,13,14,15$, and 16 carbon atoms (Table 1). The biological activity of surfactins from Bacillus sp. depends both on the peptide ring and the nature of their lipid moieties. The hemolytic activity of surfactin was enhanced by the increase in the number of carbon atoms in the fatty acid side chains, and this enhanced activity likely reflects stronger interactions with biomembranes [28].

In previous studies, the biological activities of surfactin occurred via interactions with cellular membranes, and it may have a detergent-like effect on cell membranes $[4,13]$. The many research processes that have penetrated the hydrophobic residues of the peptide moiety permeate into the membrane interface, leading to membrane permeabilization but not surface effect $[4,28]$. At higher concentrations, this detergent-like activity could stabilize leaks due to the compound's ability to generate multiple-structured polymers [28]. Although it is not yet clear whether a sub-optimal concentration $\left(\mathrm{IC}_{50} 100 \mu \mathrm{g} / \mu \mathrm{L}\right.$ ) of 
surfactin affects the cell morphology (Figure 7), surfactin-treated cells appeared to be leaky and/or lysed. Meta et al. [29]. proposed that surfactin may disturb a biochemical reaction(s) that occurs at a specific membrane site, perhaps via the long chain fatty acid, acting as a pseudosubstrate (similar to PIP3 or a farnesyl group) for either the PI3K/Akt or farnesyltransferase/Ras/ERK pathways, which promote apoptosis. The up-regulation of Bax, down-regulation of Bcl-xL, and activation of caspase- 3 proteins could confirm the apoptosis of HL-60 cell lines using bioactive Cembranoids [30]. However, the expression level of these proteins was not studied in the present study, but the morphological changes, e.g., membrane blebbing and DNA fragmentation of the MSIC, which treated Caco-2 and MCF-7 cell lines, conclude that the potential apoptosis may occur. Alongside apoptosis, autophagy or senescence may be responsible for surfactin-induced growth arrests through the induction of either the p38-mediated MAPK pathway or ROS production $[31,32]$. In a previous study, Cao et al. [33] suggested that surfactin induces apoptosis in human breast cancer MCF-7 cells through a ROS/JNK-mediated mitochondrial/caspase pathway, and that the surfactin has notable anti-tumor effects on MCF-7 cells; however, there was no obvious cytotoxicity on normal cells.

Carbohydrate and lipoprotein extracts from edible mushrooms and several bacterial cells were reported for their growth inhibition towards malignant cancer cells [34]. A number of recent studies have focused on the anticancer activities of CLP. Kameda et al. [9] provided the first evidence that CLP has anticancer activity based on the fact that extracted CLP from B. natto KMD 2311 can induce apoptosis of cancer cells. 35. Wakamatsu et al. [34] reported that the exposure of B16 cells to lipoproteins resulted in chromatin condensation, DNA fragmentation, and sub-G1 arrest. Sudo et al. [35] examined lipoproteins for their ability to inhibit growth and induce differentiation of HL60 human promyelocytic leukemia cells, and Wakamatsu et al. [34] discovered that lipoproteins induce neuronal differentiation in PC12 cells and provided the groundwork for the use of microbial extracellular CLP as a novel reagent for the treatment of cancer cells. Wang et al. [36] reported that a new CLP purified from B. subtilis subsp. natto T-2 dose-dependently inhibited the growth of human leukemia K562 cells. Kim et al. [13] examined the effects of surfactin on the proliferation of LoVo cells (a human colon carcinoma cell line) and suggested that surfactin may have anticancer properties as a result of its ability to down-regulate the cell cycle and suppress cell survival. In addition, Cao et al. [37] reported that the purified surfactin from Bacillus natto TK-1 induced the time-dependent apoptosis of human breast cancer MCF-7 cells through cell cycle arrest at the G2/M phase. In sum, the above reports and the results of our work suggest that the surfactin of B. pumilus HY1 has potential value as a novel anti-tumor agent.

The content of surfactin increased from $0.3 \mathrm{mg} / \mathrm{kg}$ on day 0 to a final content of $51.2 \mathrm{mg} / \mathrm{kg}$, corresponding to the cell concentration increases of 3.0-11.7 $\log \mathrm{CFU} / \mathrm{g}$ during cheonggukjang fermentation (Figure $5 \mathrm{~b}$ ). Several authors have studied the production of surfactin from solid-state fermentation $[4,13,27,38]$. This process is associated with the production of a higher concentration of surfactin in solid-state fermentation, which occurs in the manufacturing of soybean-fermented food [10]. In particular, Slvinski et al. [39] studied the production of surfactin through B. pumilus UFPEDA 448 in solid-state fermentation, using a medium based on okara with the addition of sugarcane bagasse as a bulking agent. This result shows that the concentration of surfactin is proportional to the concentration of cells because surfactin is produced from Bacillus sp.

The cheonggukjang is reported to have anticancer, blood pressure reduction, hypocholesterolemic, and fibrinolytic properties [4,22]. However, although these effects of cheonggukjang have been extensively studied, little is known about its potential antitumoral activities. In addition, we previously reported that the surfactin content, during cheonggukjang fermentation with B. subtilis CSY191, increased from 0.3 to $48.2 \mathrm{mg} / \mathrm{kg}$ over $60 \mathrm{~h}$ of fermentation, while the level of cytotoxic activity increased from 2.6- to 5.1-fold [4]. These findings will improve the quality of Korean traditional soybean fermented foods as 
one of the best functional foods because of their wide variety of antitumor, antimicrobial, antifungal, and antiviral activities.

\section{Materials and Methods}

\subsection{Soybean, Media, Cells, and Regents}

Soybean cultivar, namely Taekwang, was harvested and provided in 2013 from the National Institute of Crop Science of the Rural Development Administration in Korea. The tryptic soy (TS), number 3 (No. 3), and DMEM/F-12 media were purchased from Becton Dickinson Co. (Difco, Sparks, MD, USA). MCF-7 (human breast cancer cell line) and Caco-2 (human intestinal cancer cell line) were obtained from the Korean Cell Line Bank in Seoul, Korea. Sheep blood, surfactin standards (consisting of $C_{13}$ and $C_{15} \beta$ amino acids), glycerol, triglycerol, $\alpha$-cyano-4-hydroxycinnamic acid, trifluoroacetic acid, triethylamine, phenylisothiocyanate, 3-(4,5-dimethylthiazol-2-yl)-2,5-diphenyltetrazolium bromide (MTT), ethylenediaminetetraacetic acid (EDTA), dimethyl sulfoxide (DMSO), fetal bovine serum (FBS), penicillin, and streptomycin were obtained from the Sigma-Aldrich, Inc. (Merck KGaA, Darmstadt, Germany). The high-performance liquid chromatography (HPLC)-grade chloroform, methanol, water and acetonitrile were purchased from Fisher Scientific International, Inc. (Fairlawn, NJ, USA). Other regents and solvents used the analytical grade (Sigma-Aldrich, Inc., St. Louis, MO, USA).

\subsection{Indentification of HY1 Strain, and Isolation and Purification of Surfactin}

The cyclic lipopeptide producer strain HY1 was isolated from Korean soybean sauce (cheonggukjang). The cheonggukjang sample was serially diluted and grew on nutrient agar media to get a pure colony. The genomic DNA of the strain HY1 was extracted and used for amplification using Bacillus specific 16S rRNA primers: (478F 5'-TTCTACGGAGAGTTGATCC-3'; 479R, $5^{\prime}$-CACCTTCCGGTACGGCTACC-3'). The DNA sequencing and phylogenetic analysis of the HY1 strain was conducted as previously described [24]. Surfactin was isolated from strain HY1, according to Lee et al. [4] and Cho et al. [40]. The strain HY1 was cultured in $50 \mathrm{~mL}$ TS liquid medium at $30^{\circ} \mathrm{C}$ for $48 \mathrm{~h}$ to prepare bacteria. The cells were grown in $10 \mathrm{~L}$ No. 3 medium (polypeptone $10 \mathrm{~g}$, glucose $10 \mathrm{~g}, \mathrm{KH} 2 \mathrm{PO} 41 \mathrm{~g}$, and $\mathrm{MgSO} 4 \cdot 7 \mathrm{H}_{2} \mathrm{O}$ $0.5 \mathrm{~g}$ per liter, $\mathrm{pH} 6.8$ ) at $30^{\circ} \mathrm{C}$. After cultivation for 3 days, the supernatant was collected through centrifugation and adjusted to $\mathrm{pH} 2.0$ using concentrated $\mathrm{HCl}$. The precipitate was collected through centrifugation and extracted three times with methanol. The methanolic extracts were separated using thin layer chromatography on silica gel 60 plates (Merck KGaA, Darmstadt, Germany). Chloroform/methanol/water (65:25:5, v/v/v) was used as the developing solvent. The various spots were visualized by charring after spraying with concentrated sulfuric acid. To isolate the surfactin fraction, the corresponding spots were scratched from the thin-layer chromatography (TLC) plate and the silica gel material was extracted using methanol. The crude extract of surfactin was calculated at $3.25 \mathrm{gm} / \mathrm{L}$ of initial culture. For further purification, $1 \mathrm{mg}$ of extract was subjected to recycling preparative HPLC (LC-908, Japan Analytical Industry, Co., Ltd., Tokyo Japan) and HPLC JAIGEL-1H column $(C 18,250 \times 94.6 \mathrm{~mm}, 5 \mu \mathrm{m}$, Phenomenex, CA, USA) and eluted with acetonitrile/water $(1: 1, v / v)$ as the mobile phase at a flow rate of $2.5 \mathrm{~mL} / \mathrm{min}$.

\subsection{Mass Spectrometric Analysis of Surfactin Isoforms}

The purified CLP was analyzed using matrix-assisted laser desorption ionization time-of-flight mass spectrometry (MALDI-TOF MS, Vg-Instruments, Manchester, UK) and an inductively coupled plasma mass spectrometer (ICP MS; Elan Drc II, PerkinElmer Inc., New York, NY, USA). Five micrograms of sample were dissolved in DMSO-glycerol and introduced on a copper probe tip using a mixture of glycerol and triglycerol as a matrix. A saturated solution of $\alpha$-cyano-4-hydroxycinnamic acid in $70 \%$ acetonitrile $/ 0.1 \%$ trifluoroacetic acid $(1: 1, v / v)$ was mixed with an equal volume of sample for the MALDITOF mass analysis. One microliter of the sample (2 to $3 \rho \mathrm{mol})$ was deposited onto a sample 
plate and air-dried. Ions were accelerated with a voltage of $20 \mathrm{kV}$. The positive-ion and reflector mode was applied.

\subsection{Amino Acid and Mineral Analysis}

The amino acid and mineral composition analysis of the purified CLP wines were determined according to methods previously described by Cho et al. [40]. The amino acid of the purified CLP was sequenced using electrospray ionization tandem mass spectrometry (ESI-MS/MS; Finnigan-MAT TSQ 700, San Jose, CA, USA). The sample was dissolved in $50 \%$ aqueous methanol containing $1 \%$ formic acid prior to injection into the mass spectrometer. ESI-MS/MS spectra were acquired after inducing collisions between precursor ions and nitrogen collision gas at acceleration voltages of $50 \mathrm{~V}$.

\subsection{Preparation and Fermentation of Cheonggukjang}

Soybeans $(1 \mathrm{~kg})$ were washed and soaked with three times volume of tap water at $20 \pm 2{ }^{\circ} \mathrm{C}$ for $12 \mathrm{~h}$, followed by steaming for $30 \mathrm{~min}$ at $121 \pm 1{ }^{\circ} \mathrm{C}$. The steamed soybeans were incubated at $37^{\circ} \mathrm{C}$ for $1 \mathrm{~h}$ to cool down the sample. The cooked soybeans were subsequently inoculated with 5\% $(v / w)$ HY1 $(7.43 \log \mathrm{CFU} / \mathrm{mL})$, fermented for $60 \mathrm{~h}$ at $37 \pm 2{ }^{\circ} \mathrm{C}$ and sampled at $0,12,24,36,48$, and $60 \mathrm{~h}$. The growth of strain HY1 during fermentation was determined as viable cell counts at each time point. One gram of the sample was mixed with $9 \mathrm{~mL}$ of $0.85 \% \mathrm{NaCl}$ solution, and the dilutions were spread onto TS agar plates. Colonies were counted after incubation at $37^{\circ} \mathrm{C}$ for $24 \mathrm{~h} \mathrm{[22].}$

\subsection{Extraction and Analysis of Surfactin}

The extraction and analysis of surfactin were performed according to Lee et al. [4] methods. Ten grams of ground cheonggukjang were extracted using $30 \mathrm{~mL}$ of methanol and adjusted to $\mathrm{pH} 2.0$ with concentrated $\mathrm{HCl}$ by shaking $(160 \mathrm{rpm})$ at $30^{\circ} \mathrm{C}$ for $12 \mathrm{~h}$. The extract was filtered through Whatman No. 2 filter paper and dried under a vacuum. The dried material was redissolved in $10 \mathrm{~mL}$ of $80 \%$ methanol and filtered through a $0.45-\mu \mathrm{m}$ Millipore PVDF filter (Schleicher \& Schuell, GmbH, Dassel, Germany). The filtrate was used for HPLC analysis to determine the surfactin concentration during the fermentation of cheonggukjang. The injection volume of the sample was $20 \mu \mathrm{L}$. The surfactin was analyzed through HPLC (Perkin-Elmer 200 series, Perkin-Elmer Corp., Norwalk, CT, USA) using an RP C18 column $(4.6 \times 250 \mathrm{~mm}, 5 \mu \mathrm{m}$, Waters Corp., Milford, MA, USA). The acetonitrile:water $(1: 1, v / v)$ was eluted at a flow rate of $1 \mathrm{~mL} / \mathrm{min}$ at $40^{\circ} \mathrm{C}$. Surfactin was measured at $214 \mathrm{~nm}$ using a UV detector (Perkin-Elmer UV 200 series, Perkin-Elmer Corp., Norwalk, CT, USA). The concentration of surfactin was determined using a standard curve with standard solutions at $25,50,75$, and $100 \mu \mathrm{g} / \mathrm{mL}$.

\subsection{MTT Assay}

MCF-7 and Caco-2 cells were used as cancer cell lines for the MTT assay. The cells were cultured in DMEM/F-12 medium, supplemented with 10\% FBS and 1\% penicillinstreptomycin. The MTT assay was determined by the method of Lee et al. [4]. Briefly, the two cancer cells were dissociated with $0.05 \%$ trypsin- $0.02 \%$ EDTA, and $180 \mu \mathrm{L}$ of the cell suspension $\left(1 \times 10^{4}\right.$ cells $\left./ \mathrm{mL}\right)$ was seeded onto 48 -well microtiter plates and treated with various concentrations of mixture of five surfactin isoforms of cheonggukjang $(20 \mu \mathrm{L})$. After incubation for $24 \mathrm{~h}, 20 \mu \mathrm{L}$ of MTT solution $(2.5 \mathrm{mg} / \mathrm{mL}$ PBS) was added. The formazan dye was solubilized by adding $150 \mu \mathrm{L}$ of DMSO to each well, followed by gentle shaking. The optical densities were read on an ELISA reader (680; Bio-Rad, Tokyo, Japan) at $540 \mathrm{~nm}$. The analysis of DNA fragmentation was determined by an electrophoresis method.

\section{Conclusions}

We identified five potential isoforms of surfactin from B. pumilus HY1. Surfactin is a significant component of the stain HY1-fermented cheonggukjang, with surfactin reaching $51.2 \mathrm{mg} / \mathrm{kg}$ at the end of fermentation $(60 \mathrm{~h})$. Surfactin extraction of cheonggukjang had 
antiproliferative activity against two cancer cells lines. Further studies are needed to define the in vivo cytotoxic effects of surfactin and clarify its precise molecular mechanism(s) of action.

Author Contributions: S.-Y.H. performed the experiments, analyzed the data, and writing-original draft. D.-H.L. formal analysis and commented and edited the manuscript. J.-H.L. and M.A.H. performed the experiments, formal analysis, and analyzed the data. K.-M.C. funding acquisition, conceived and designed the experiments, interpreted the data and prepared the manuscript. All authors have read and agreed to the published version of the manuscript.

Funding: This research was supported by the Basic Science Research Program through the National Research Foundation (NRF) funded by the Ministry of Education (Grant number 2016R1D1A1B01009898), Republic of Korea and the Bio \& Medical Technology Development Program through the National Research Foundation (NRF) funded by the Ministry of Science \& ICT (Grant number 2020M3A9I3038560), Republic of Korea.

Informed Consent Statement: Informed consent was obtained from all subjects involved in the study.

Data Availability Statement: Data reported in this study is contained within the article. The underlying raw data is available on request from the corresponding author.

Conflicts of Interest: The authors declare that there is no conflict of interests regarding the publication of this paper.

Sample Availability: Samples of the compounds were isolated in small amounts from Bacillus pumilus HY1 according to ref. [24] and are no longer available.

$\begin{array}{ll}\text { Abbreviations } & \\ \text { CLP } & \text { cyclic lipopeptide } \\ \text { MSIC } & \text { mixture of five surfactin isoforms of cheonggukjang } \\ \text { TS } & \text { tryptic soy } \\ \text { No. 3 } & \text { 3umber 3 } \\ \text { MTT } & \text { ethylenediaminetetraacetic acid } \\ \text { EDTA } & \text { dimethyl sulfoxide } \\ \text { DMSO } & \text { fetal bovine serum } \\ \text { FBS } & \text { matrix-assisted laser desorption ionization time-of-flight mass spectrometry } \\ \text { MALDI-TOF MS } & \text { electrospray ionization tandem mass spectrometry } \\ \text { ESI-MS/MS } & \text { high performance liquid chromatography } \\ \text { HPLC } & \end{array}$

\section{References}

1. From, C.; Hormazabal, V.; Hardy, S.P.; Granum, P.E. Cytotoxicity in Bacillus mojavensis is abolished following loss of surfactin synthesis: Implications for assessment of toxicity and food poisoning potential. Int. J. Food Microbiol. 2007, 117, 43-49. [CrossRef]

2. Kalinovskaya, N.I.; Kuznetsova, T.A.; Ivanova, E.P.; Romanenko, L.A.; Voinov, V.G.; Huth, F.; Laatsch, H. Characterization of surfactin-like cyclic depsipeptides synthesized by Bacillus pumilus from ascidian Halocynthia aurantium. Mar. Biotechnol. 2002, 4, 179-188. [CrossRef] [PubMed]

3. Koumoutsi, A.; Chen, X.H.; Henne, A.; Liesegang, H.; Hitzeroth, G.; Franke, P.; Vater, J.; Borriss, R. Structural and functional characterization of gene clusters directing nonribosomal synthesis of bioactive cyclic lipopeptides in Bacillus amyloliquefaciens strain FZB42. J. Bacteriol. 2004, 186, 1084-1096. [CrossRef] [PubMed]

4. Lee, J.H.; Nam, S.H.; Seo, W.T.; Yun, H.D.; Hong, S.Y.; Kim, M.K.; Cho, K.M. The production of surfactin during the fermentation of cheonggukjang by potential probiotic Bacillus subtilis CSY191 and the resultant growth suppression of MCF-7 human breast cancer cells. Food Chem. 2012, 131, 1347-1354. [CrossRef]

5. Thaniyavarn, J.; Roongsawang, N.; Kameyama, T.; Haruki, M.; Imanaka, T.; Morikawa, M.; Kanaya, S. Production and characterization of biosurfactants from Bacillus licheniformis F2.2. Biosci. Biotechnol. Biochem. 2003, 67, 1239-1244. [CrossRef]

6. Schwarzer, D.; Finking, R.; Marahiel, M.A. Nonribosomal peptides: From genes to products. Nat. Prod. Rep. 2003, 20, $275-287$. [CrossRef]

7. Li, H.; Gilchrist, C.L.M.; Phan, C.S.; Lacey, H.J.; Vuong, D.; Moggach, S.A.; Lacey, E.; Piggott, A.M.; Chooi, Y.H. Biosynthesis of a new benzazepine alkaloid nanangelenin a from Aspergillus nanangensis involves an unusual l-kynurenine-incorporating NRPS catalyzing regioselective lactamization. J. Am. Chem. Soc. 2020, 142, 7145-7152. [CrossRef] 
8. Dose, B.; Ross, C.; Niehs, S.P.; Scherlach, K.; Bauer, J.P.; Hertweck, C. Food-poisoning bacteria employ a citrate synthase and a type II NRPS to synthesize bolaamphiphilic lipopeptide antibiotics. Angew. Chem. Int. Ed. 2020, 59, 21535-21540. [CrossRef]

9. Niehs, S.P.; Dose, B.; Richter, S.; Pidot, S.; Dahse, H.M.; Stinear, T.P.; Hertweck, C. Mining symbionts of a spider-transmitted fungus illuminates uncharted biosynthetic pathways to cytotoxic benzolactones. Angew. Chem. Int. Ed. 2020, 59, 7766-7771. [CrossRef] [PubMed]

10. Symmank, H.; Franke, P.; Saenger, W.; Bernhard, F. Modification of biologically active peptides: Production of a novel lipohexapeptide after engineering of Bacillus subtilis surfactin synthetase. Protein Eng. 2002, 15, 913-921. [CrossRef]

11. Hue, N.; Serani, L.; Laprevote, O. Structural investigation of cyclic peptidolipids from Bacillus subtilis by high-energy tandem mass spectrometry. Rapid Commun. Mass Spectrom. 2001, 15, 203-209. [CrossRef]

12. Kameda, Y.; Oira, S.; Matsui, K.; Kanatomo, S.; Hase, T. Antitumor activity of Bacillus natto. V. Isolation and characterization of surfactin in the culture medium of Bacillus natto KMD 2311. Chem. Pharm. Bull. 1974, 22, 938-944. [CrossRef]

13. Kim, K.M.; Lee, J.Y.; Kim, C.K.; Kang, J.S. Isolation and characterization of surfactin produced by Bacillus polyfermenticus KJS-2. Arch. Pharm. Res. 2009, 32, 711-715. [CrossRef] [PubMed]

14. Vollenbroich, D.; Ozel, M.; Vater, J.; Kamp, R.M.; Pauli, G. Mechanism of inactivation of enveloped viruses by the biosurfactant surfactin from Bacillus subtilis. Biologicals 1997, 25, 289-297. [CrossRef]

15. Tsukagoshi, N.; Tamura, G.; Arima, K. A novel protoplast bursting factor (surfactin) obtained from Bacillus subtilis IAM1213. I. The effects of surfactin on Bacilllus megaterium KM. Biochim. Biophys. Acta 1970, 196, 204-210. [CrossRef]

16. Hwang, M.H.; Chang, Z.Q.; Kang, E.H.; Lim, J.H.; Yun, H.I.; Rhee, M.H.; Jeong, K.S.; Park, S.C. Surfactin C inhibits Mycoplasma hyopneumoniae-induced transcription of proinflammtory cytokines and nitric oxide production in murin RAW 264.7 cells. Biotechnol. Lett. 2008, 30, 229-233. [CrossRef]

17. Morán, A.C.; Martínez, M.A.; Siñeriz, F. Quantification of surfactin in culture supernatants by hemolytic activity. Biotechnol. Lett. 2002, 24, 177-180. [CrossRef]

18. Kikuchi, T.; Hasumi, K. Enhancement of plasminogen activation by surfactin C: Augmentation of fibrinolysis in vitro and in vivo. Biochim. Biophys. Acta 2002, 29, 234-245. [CrossRef]

19. Arima, K.; Kakinuma, A.; Tamura, G. Surfactin, a crystalline peptide lipid surfactant produced by Bacillus subtilis: Isolation, characterization and its inhibition of fibrin clot formation. Biochem. Biophys. Res. Commun. 1968, 31, 488-494. [CrossRef]

20. Hosono, K.; Suzuki, H. Acylpeptides, the inhibition of cyclic adenosine $3^{\prime}, 5^{\prime}$ monophosphate phosphodiesterase. III. Inhibition of cyclic AMP phosphodiesterase. J. Antibiot. 1983, 36, 679-683. [CrossRef]

21. Kim, K.; Jung, S.Y.; Lee, D.K.; Jung, J.; Park, J.K.; Kim, D.K.; Lee, C. Suppression of inflammatory responses by surfactin, a selective inhibitor of platelet cytosolic phospholipase A2. Biochem. Pharmacol. 1998, 55, 975-985. [CrossRef]

22. Cho, K.M.; Hong, S.Y.; Math, R.K.; Lee, J.H.; Kambiranda, D.M.; Kim, J.M.; Islam, S.M.A.; Yun, M.G.; Cho, J.J.; Lim, W.J.; et al. Biotransformation of phenolics (isoflavones, flavanols and phenolic acids) during the fermentation of cheonggukjang by Bacillus pumilus HY1. Food Chem. 2009, 114, 413-419. [CrossRef]

23. Cho, K.M.; Lee, J.H.; Yun, H.D.; Ahn, B.Y.; Kim, H.; Seo, W.T. Changes of phytochemical constituents (isoflavones, flavanols, and phenolic acids) during cheonggukjang soybeans fermentation using potential probiotics Bacillus subtilis CS90. J. Food Compost. Anal. 2011, 24, 402-410. [CrossRef]

24. Cho, K.M.; Math, R.K.; Hong, S.Y.; Islam, S.M.A.; Mandanna, D.K.; Cho, J.J.; Yun, M.G.; Kim, J.M.; Yun, H.D. Iturin produced by Bacillus pumilus HY1 from Korean soybean sauce (kanjang) inhibits of aflatoxin producing fungi. Food Cont. 2009, 20, 402-406. [CrossRef]

25. Baumgart, F.; Kluge, C.; Ullrich, B.; Vater, J.; Ziessow, D. Identification of amino acid substitutions in the lipopeptide surfactin using 2D NMR spectroscopy. Biochem. Biophys. Res. Commun. 1991, 177, 998-1005. [CrossRef]

26. Vallet, M.; Vanbellingen, Q.P.; Fu, T.; Caer, J.P.L.; Della-Negra, S.; Touboul, D.; Duncan, K.R.; Nay, B.; Brunelle, A.; Prado, S. An integrative approach to decipher the chemical antagonism between the competing endophytes Paraconiothyrium varialbile and Bacillus subtilis. J. Nat. Prod. 2017, 80, 2863-2873. [CrossRef]

27. Zhu, Z.; Zhang, F.; Wei, Z.; Ran, W.; Shen, Q. The usage of rice straw as a major substrate for the production of surfactin by Bacillus amyloliquefaciens XZ-173 in solid-state fermentation. J. Environ. Manag. 2013, 127, 96-102. [CrossRef] [PubMed]

28. Heerklotz, H.; Seelig, J. Leakage and lysis of lipid membranes induced by the lipopeptide surfactin. Eur. Biophys. J. 2006, 35, 305-314. [CrossRef] [PubMed]

29. Meta, M.; Yang, S.H.; Bergo, M.O.; Fong, L.G.; Young, S.G. Protein farnesyltransferase inhibitors and progeria. Trends Mol. Med. 2006, 12, 480-487. [CrossRef] [PubMed]

30. Kamada, T.; Kang, M.C.; Phan, C.S.; Zanil, I.I.; Jeon, Y.J.; Vairappan, C.S. Bioactive cembranoids from the soft coral genus Sinularia sp. in Borneo. Mar. Drugs 2018, 16, 99. [CrossRef]

31. Yamakami, Y.; Kensuke, K.; Yonekura, R.; Kudo, I.; Fujii, M.; Ayusawa, D. Molecular basis for premature senescence induced by surfactants in normal human cells. Biosci. Biotechnol. Biochem. 2014, 78, 2022-2029. [CrossRef] [PubMed]

32. Zhao, H.; Yan, L.; Xu, X.; Jiang, C.; Shi, J.; Zhang, Y.; Liu, L.; Lei, S.; Shao, D.; Huang, Q. Potential of Bacillus subtilis lipopeptides in anti-cancer I: Induction of apoptosis and paraptosis and inhibition of autophagy in K562 cells. AMB Express 2018, 8, 78. [CrossRef]

33. Cao, X.H.; Wang, A.H.; Wang, C.L.; Mao, D.Z.; Lu, M.F.; Cui, Y.Q.; Jiao, R.Z. Surfactin induces apoptosis in human breast cancer MCF-7 cells through a ROS/JNK-mediated mitochondrial/caspase pathway. Chem. Biol. Interact. 2010, 183, 357-362. [CrossRef] 
34. Wakamatsu, Y.; Zhao, X.; Jin, C.; Day, N.; Shibahara, M.; Nomura, N. Manno-sylerythritol lipid induces characteristics of neuronal differentiation in PC12 cells through an ERK-related signal cascade. Eur. J. Biochem. 2001, 268, 374-383. [CrossRef] [PubMed]

35. Sudo, T.; Zhao, X.; Wakamatsu, Y.; Shibahara, M.; Nakahara, T. Induction of the differentiation of human HL-60 promyelocytic leukemia cell line by succinoyl trehalose lipids. Cytotechnology 2000, 33, 259-264. [CrossRef]

36. Wang, C.L.; Ng, T.B.; Yuan, F.; Liu, Z.K.; Liu, F. Induction of apoptosis in human leukemia K562 cells by cyclic lipopeptide from Bacillus subtilis natto T-2. Peptides 2007, 28, 1344-1350. [CrossRef]

37. Cao, X.H.; Wang, A.H.; Jiao, R.Z.; Wang, C.L.; Mao, D.Z.; Yan, L.; Zeng, B. Surfactin induces apoptosis and G2/M arrest in human breast cancer MCF-7 cells through cell cycle factor regulation. Cell Biochem. Biophys. 2009, 55, 163-171. [CrossRef]

38. Ohno, A.; Ano, T.; Shoda, M. Production of a lipopeptide antibiotic surfactin with recombinant Bacillus subtilis. Biotechnol. Lett. 1992, 14, 1165-1168. [CrossRef]

39. Slvinski, C.T.; Mallmann, E.; de Araújo, J.M.; Mitchell, D.A.; Krieger, N. Production of surfactin by Bacillus pumilus UFPEDA 448 in solid-state fermentation using medium based on okara with sugarcane bagasse as a bulking agent. Proc. Biochem. 2012, 47, 1848-1855. [CrossRef]

40. Cho, S.J.; Hong, S.Y.; Kim, J.Y.; Park, S.R.; Kim, M.K.; Lim, W.J.; Shin, E.C.; Kim, E.J.; Cho, Y.U.; Yun, H.D. Endophytic Bacillus sp. CY22 from a balloon flower (Platycodon grandiflorum) produces surfactin isoforms. J. Microbiol. Biotechnol. 2003, 13, 859-865. 